\title{
João Goulart: do limbo à escrita da história
}

João Goulart: del olvido a las páginas de la Historia

João Goulart: from oblivion to making history

João Goulart: de l'oubli à écriture de l'histoire

Lucilia de Almeida Neves Delgado[1]

\section{FERREIRA, Jorge. João Goulart: uma biografia. Rio de Janeiro: Civilização Brasileira, 2011.714 p.}

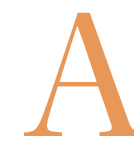

história e a memória, embora diferentes em suas formas de registro e manifestação, são férteis interlocutoras. Ambas, como bem acentua Jacques Le Goff, são dotadas de expressivos poderes, entre eles destacam-se, por exemplo, os de construção do esquecimento, da desqualificação e da interdição de registros. Por outro lado, a memória e a história também ganham poderosa expressão ao construírem versões positivas e elogiosas de eventos e pessoas. Quando assim acontece, essas características muitas vezes contribuem para alicerçar dinâmicas de mitificação de pessoas e processos sociais. As duas situações, desqualificação e mitificação, distorcem a realidade. Ao conhecimento histórico analítico e bem fundamentado, cabe romper com a cadeia nebulosa construída por essas estratégias referentes ao vivido e ao acontecido.

O livro João Goulart: uma biografia, do historiador Jorge Ferreira, alcança com esmero o objetivo de construir um conhecimento histórico sólido, posto que é interpretativo e bem fundamentado. Trata-se de um texto que inclui inúmeras contribuições para um melhor entendimento da história do Brasil no pós-1945. O mesmo teve como mérito especial romper com pressupostos e chavões que ilharam o ex-presidente Goulart, no âmbito de uma memória de esquecimento, de desqualificação ou de interdição, e trazê-lo para o campo da história do conhecimento.

Desde a tomada do poder pelos generais presidentes em 1964, a memória do presidente João Goulart tem frequentado a zona etérea e nebulosa do limbo. Uma pátina de esquecimento há muitos anos encobre sua trajetória, que, ao contrário do que está consolidado no senso comum, apesar de permeada por crises, foi rica e marcada por expressiva e destacada participação em cargos públicos.

Tal estratégia da construção de uma memória de esquecimento sobre o ex-presidente consolidou-se graças ao forte empenho dos adversários políticos que o depuseram. A mesma teve dois objetivos: justificar o próprio golpe 
de estado e construir uma possível legitimidade para o regime autoritário. Porém outros fatores também integram o caleidoscópio que a explica e a reproduz. Entre os mesmos, destaca-se a construção interpretativa produzida em especial nas décadas de 1970 e 1980 por intelectuais de renome, como Florestan Fernandes, os quais identificam em Jango uma forte fragilidade política e uma ambiguidade escorregadia quanto à sua opção ideológica à esquerda. Ainda, o silêncio recorrente de jornais e revistas, de expressiva circulação, adensou o caldo da desqualificação e do esquecimento sobre Goulart.

A biografia de Jango, escrita por de Jorge Ferreira, é baseada em sólida pesquisa documental e bibliográfica. São informações retiradas de livros, crônicas, documentos oficiais, artigos de revistas e jornais, manifestos, discursos, fotos, livros de memória, e articuladas em um texto que tem o mérito de ser denso, mas fluente. $\mathrm{O}$ autor ainda recorreu à realização de entrevistas que trouxeram grande contribuição e um toque de emoção à sua escrita. Por essas qualidades, o livro, redigido com clareza e cuidado estético, contribui de forma efetiva para a desconstrução da injustiça referente aos eventos que levaram à desqualificação do presidente Jango como um homem público. Desqualificação elaborada com esmero estratégico que não poupa o uso frequente de adjetivos negativos para identificar o ex-presidente, en-

Foram dez anos dedicados à investigação e
redação de uma longa e agradável biografia
[...] um resultado impressionante, combinando
registro biográfico e história

tre eles destacam-se expressões como demagogo, incompetente, irresponsável, boêmio e populista.

A combinação das estratégias de construção e reprodução do esquecimento e da difusão de críticas generalizadas sobre João Goulart teve como desdobramento um grande silêncio sobre sua trajetória política. Tal fato fica mais evidente quando compara-se o número de livros e artigos publicados sobre o líder com a profusão de publicações sobre Getúlio Vargas e Juscelino Kubitschek, que atuaram na mesma fase histórica em que Jango alcançou projeção nacional. Cabe lembrar que Goulart foi ministro do trabalho durante o Governo Vargas (quando ganhou projeção nacional), deputado federal pelo Rio Grande do Sul, vice-presidente de Juscelino Kubitschek e de Jânio Quadros e, por fim, presidente da República.

Jorge Ferreira, embora atento às ambiguidades que marcaram a trajetória de Jango, está na contramão da solidificada imagem negativa do ex-presidente. Sem cair na tentação de se apresentar como redentor da memória do presidente deposto em 1964, o autor escreveu um texto ponderado, sério e marcado por qualidades inerentes à construção do conhecimento histórico: pesquisa, registro dos fatos e interpretação do processo. Foram dez anos 
dedicados à investigação e redação de uma longa e agradável biografia. Dez anos de persistência e dedicação meticulosa a um objetivo que teve um resultado impressionante, combinando registro biográfico e história.

O livro percorre a trajetória de vida de João Goulart desde sua infância até sua morte, no exílio em 1976. Buscou, nas entranhas do Rio Grande do Sul e nas características familiares de Jango, elementos de formação da personalidade de um político, que, apesar de ter herdado sólida fortuna e de tê-la multiplicado com efetiva competência, sempre possuiu uma afinidade eletiva com os segmentos mais empobrecidos da população brasileira. Essa opção preferencial do ex-presidente - trabalhadores urbanos e rurais - jamais foi compreendida e aceita pelos setores mais conservadores da sociedade brasileira, que se articularam na aliança político-social atuante na deposição do ex-presidente. Esta aliança era formada pelos seguintes protagonistas: expressivos segmentos das forças armadas, partidos como a União Democrática Nacional, grandes proprietários de terra - que o viam como traidor, membros da igreja católica conservadora, governadores de estado - como Minas Gerais, Guanabara e São Paulo, empresas de capital externo que investiam no Brasil e organizações internacionais que se tornaram guardiãs do sistema capitalista no tempo da Guerra Fria.

Ferreira demonstrou que, desde jovem, Jango, como era conhecido em São Borja, sua cidade natal, tinha algumas qualidades merecedoras de importância e que foram melhor elaboradas ao longo de sua vida de homem público. Era paciente e exímio negociador, como demonstrou durante seu mandato de vice-presidente à época do governo de Kubitschek. Sobretudo, tinha vocação para a arte da política e, em especial, à formação de consensos. A essas virtudes, contudo, somaram-se defeitos, como os de muitas vezes buscar a construção da conciliação com adversários e frágeis apoiadores. Esses últimos não hesitaram em chamuscá-lo com o que atualmente é denominado de 'fogo amigo'. Essa orientação do presidente, ou seja, buscar a conciliação mesmo quando os sinais indicavam sua inviabilidade, poderia ser um estilo e uma estratégia, mas acabou sendo identificada como vacilação, incapacidade decisória e demagogia populista.

O escritor também argumenta, de forma correta e bem fundamentada, que, diferentemente do que é disseminado, não se pode definir Jango como um populista sem méritos e sem tradição histórica. Ao contrário, identifica-o como o principal herdeiro de Vargas - embora dele se diferenciasse - e um dos maiores líderes não do populismo, mas do trabalhismo brasileiro. Para ele, a principal opção política de Goulart era o trabalhismo, desdobrado em nacionalismo, desenvolvimentismo, distributivismo social e intervencionismo estatal. Certamente, Jango estava sintonizado com expressivos políticos e intelectuais da sua época, os quais consideravam ser de responsabilidade do Estado a adoção e a administração de políticas públicas sociais e econômicas.

A biografia de Goulart coroa renovadora contribuição historiográfica de Ferreira a respeito do período entre 1945 a 1964. Seu principal investimento no que se refere à política desses anos situa-se no esforço para desconstruir a teoria do populismo. Discorda da conceituação dela decorrente, que identifica populismo como manipulação e demagogia. Portanto, diverge 
veementemente da utilização desse conceito como explicativo daquele período, pois entende que trabalhismo e nacional desenvolvimentismo são ideias mais consistentes e melhor explicativas de uma opção política, hegemônica à época e orientada por um projeto nacional caracterizado por definições precisas e objetivos estabelecidos. Entre as metas destacavam-se valorização do trabalho, distributivismo social, planejamento estatal, valorização dos investidores nacionais, política previdenciária sólida e reformismo social, com ênfase para a reforma agrária.

Sem se descuidar dos aspectos privados da trajetória do ex-presidente, que gostava dos prazeres da vida boêmia e do cotidiano na área rural, Jorge Ferreira também registrou, em três densos capítulos, a vida do líder no tempo do exílio. Foram anos de amargura, saudade e solidão. Nessa derradeira fase de sua vida, à Goulart só restou o prazer de cuidar de suas extensas criações de gado que, contudo, estavam, em grande parte, situadas na Argentina e no Uruguai e não em sua pátria.

Jango rumou para o exílio, pensando que o mesmo duraria pouco, tão logo os militares ascenderam ao poder em 1964. Seguiu acompanhado de sua mulher Maria Tereza e de seus filhos João Vicente e Denize. Sua opção foi a de não resistir ao golpe que o destituíra. Para muitos de seus aliados seu

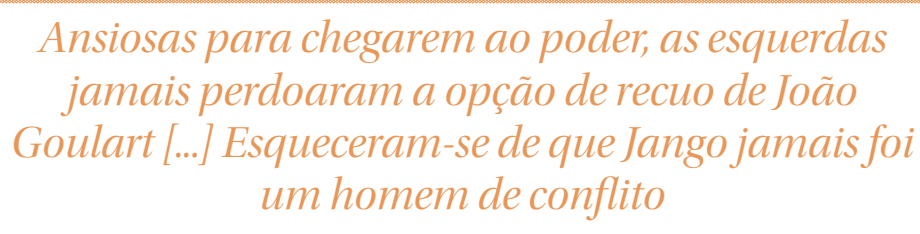

grande erro foi exatamente o de não ter reagido ao golpe. No entanto, Ferreira argumenta que o presidente preferiu o caminho do exílio, com toda sua imprevisibilidade, ao recurso da resistência, que, com grande probabilidade, mergulharia o Brasil em uma guerra civil. Essa mesma orientação o levou a concordar, embora contrariado, com a adoção do parlamentarismo, em 1961, quando da renúncia do presidente Jânio Quadros.

A decisão de não resistir ao Golpe de 1964 contrariou diferentes tendências das esquerdas brasileiras, que ganhavam envergadura no efervescente pré-1964. Ansiosas para chegarem ao poder, as esquerdas jamais perdoaram a opção de recuo de João Goulart quando as botas dos militares alcançaram o Palácio do Planalto, os marines americanos rondavam as costas brasileiras e o Congresso Nacional, apesar dos protestos de alguns deputados, declarou vaga a Presidência da República, mesmo estando Goulart em território nacional. Esqueceram-se de que Jango jamais foi um homem de conflito. Ao contrário, sempre escolheu a via da conciliação e da negociação, entendida por ele como inerente à democracia.

O mesmo João Goulart, que sempre fora conciliador e trabalhista, abraçou, com vigor, o radicalismo reformista no final do ano de 1963 e início de 1964. Após inúmeras tentativas, sem ressonância, de negociação com os setores mais conservadores da sociedade brasileira, recorreu ao apoio das esquerdas para sua sustentação no poder. Tal estratégia orientou a regulamentação 
da lei, que controlava a remessa de lucros por empresas de capital internacional instaladas no Brasil, e a adoção de medidas como a da reforma agrária, anunciada no comício de 13 de março de 1964.

Para Ferreira, a conspiração conservadora a depô-lo ganhou forma e envergadura a partir desse contexto. Portanto, concluímos que nesse ponto o autor carregou um pouco na tinta, pois em 1954, quando da crise política que levou ao suicídio de Getúlio Vargas, os acontecimentos de 1964 já haviam sido anunciados. As circunstâncias adversas do governo Jango e o movimento das peças no xadrez da história somente definiram o tempo exato desse desfecho.

Finalmente, vale ressaltar que, nesta alentada biografia, Ferreira esclareceu seu entendimento sobre qual foi o papel, no contexto do imediato pré-golpe de 1964, das divergentes forças políticas que atuavam naqueles anos. Considerou que a conjuntura foi marcada por marchas e contramarchas e por um forte radicalismo à direita e à esquerda. Esse processo radical dificultou uma avaliação melhor acurada dos possíveis desdobramentos decorrentes da extrema polarização conjuntural. Nesse quadro de crescente intransigência, também alimentada pelos acontecimentos da Guerra Fria, a vocação negociadora de Goulart não encontrou eco e não teve força persuasiva. À uma determinada altura dos acontecimentos, que define como o ano de 1963, não foi mais possível conter o avanço da oposição ou neutralizar a força da radicalização política à esquerda que se movimentava sob forte influência do brizolismo. Contudo, mesmo reafirmando a tese do crescente radicalismo, deixou registrado que os opositores do trabalhismo, do nacionalismo e do reformismo foram os protagonistas principais do golpe de 1964. Em outras palavras, os responsáveis pelo golpe situavam-se no campo da direita.

Uma biografia do porte e da qualidade de escrita do historiador Jorge Ferreira é leitura indispensável para quem quer conhecer melhor o tempo polêmico e efervescente do pré-1964 e seus terríveis desdobramentos, uma vez que o livro se estende até a morte de Goulart, em 1976, quando o presidente ainda estava no exílio. Entre os méritos do autor, que são muitos, destaca-se o da ousadia de se contrapor à história hegemônica e à construção do esquecimento coletivo sobre quem foi um protagonista vencido e não vencedor. Mais do que isso, o historiador demonstrou que Jango foi um homem público de grande envergadura, merecendo transitar, de forma definitiva, do limbo para as páginas da história. 
